\title{
Tanshinone IIA inhibits human breast cancer MDA-MB-231 cells by decreasing LC3-II, Erb-B2 and NF-кBp65
}

\author{
CHIN-CHENG SU ${ }^{1,3-5}$, SU-YU CHIEN ${ }^{2}$, SHOU-JEN KUO ${ }^{1,6}$, YAO-LI CHEN ${ }^{1,6}$, \\ CHUN-YUAN CHENG ${ }^{1,6}$ and DAR-REN CHEN ${ }^{1,3,6}$
}

\begin{abstract}
Departments of ${ }^{1}$ Surgery, and ${ }^{2}$ Pharmacy, ${ }^{3}$ Comprehensive Breast Cancer Center, Changhua Christian Hospital, Changhua 500-06; ${ }^{4}$ Mingdao University, Changhua 52345; ${ }^{5}$ China Medical University, Taichung 40402;

${ }^{6}$ Institute of Medicine, Chung Shan Medical University, Taichung 40201, Taiwan, R.O.C.
\end{abstract}

Received October 11, 2011; Accepted January 9, 2012

DOI: $10.3892 / \mathrm{mmr} .2012 .756$

\begin{abstract}
The ability of tanshinone IIA (Tan-IIA) to inhibit the proliferation of human breast cancer cell lines in vitro and in vivo is well documented. However, the molecular mechanisms have not been fully elucidated. In the present study, MDA-MB-231 cells were treated with different concentrations of Tan-IIA for $48 \mathrm{~h}$, followed by protein extraction for western blotting. For an in vivo study, MDA-MB-231 cells were implanted directly into female SCID mice which were divided randomly into three groups to be treated with vehicle, Tan-IIA $(20 \mathrm{mg} / \mathrm{kg})$ and Tan-IIA $(60 \mathrm{mg} / \mathrm{kg})$ every other day orally, with treatment starting 4 weeks after inoculation with the MDA-MB-231 cells. The results showed that Tan-IIA inhibited the proliferation of MDA-MB-231 cells and decreased the protein expression of LC3-II and Erb-B2 in vitro. Treatment with Tan-IIA (20 or $60 \mathrm{mg} / \mathrm{kg}$ ) for 90 days resulted in a reduction in tumor size and weight compared to the control group. The protein expression of NF-кBp65 was reduced, while caspase- 3 was up-regulated compared to the control group. These findings indicate that Tan-IIA inhibits tumor growth in a MDA-MB-231 xenograft animal model. One of the molecular mechanisms may be through a decrease in NF-кBp65 and an increase in caspase-3 expression.
\end{abstract}

\section{Introduction}

Based on the GLOBOCAN 2008 estimates, breast cancer is the leading cause of cancer-related death in women worldwide. New cases of breast cancer are estimated to be 1,383,500 with 458,400 deaths (1). Many prescriptions for chemotherapy have

Correspondence to: Dr Chin-Cheng Su, Department of Surgery, Comprehensive Breast Cancer Center, Laboratory of Integrative Medicine Cancer Research, Changhua Christian Hospital, 135 Nan-Hsiao Street, Changhua 500-06, Taiwan, R.O.C.

E-mail: succ.maeva@msa.hinet.net

Key words: tanshinone IIA, MDA-MB-231 cells, LC3-II, Erb-B2, $\mathrm{NF}-\kappa \mathrm{Bp} 65$ been derived from plants (2). Danshen (Salviae miltiorrhizae radix) has been used in traditional Chinese medicine for cardiovascular disease and appeared in the Chinese book, Shennong Bencao Jing (ca. 100 A.D.) (3). Tanshinone IIA (Tan-IIA) was extracted from danshen and was first described in 1968. It is known to have antioxidant (4) and anti-inflammatory properties (5). Our previous studies showed that Tan-IIA induces apoptosis in certain human cancer cells, such as human colon cancer colo 205 cells $(6,7)$, human hepatocellular carcinoma hep-J5 cells (8), small-cell lung cancer H146 cells (9) and nonsmall-cell lung cancer A549 cells (10). Our previous study also showed that Tan-IIA inhibited MDA-MB-231 cells through inducing apoptosis by increasing $\mathrm{Bax}$ to $\mathrm{Bcl}-\mathrm{xL}$ ratios and the protein levels of $\mathrm{p} 21$ and caspase- 8 in vitro (11). The anticancer effects of Tan-IIA on human breast cancer cell lines in vitro and in vivo have been well documented (12-15). However, the molecular mechanisms have not been fully elucidated. In the present study, we evaluated the effects and molecular mechanisms of Tan-IIA on MDA-MB-231 cells in vitro using a human breast cancer xenograft model in SCID mice.

\section{Materials and methods}

Chemicals. Tan-IIA (molecular formula: $\mathrm{C}_{19} \mathrm{H}_{18} \mathrm{O}_{3}$, purity $>96 \%$ by HPLC) was purchased from Herbasin Co. (Shenyang, China). Corn oil, aprotinin, antipain, sodium deoxycholate, leupeptin, sodium orthovanadate, Triton X-100, Tris- $\mathrm{HCl}$, ribonuclease-A and MTT [3-(4,5-dimethylthiazol-2-y1)2,5-diphenyltetrazolium bromide] were obtained from Sigma Chemical Co. (St. Louis, MO, USA). Dimethyl sulfoxide (DMSO), potassium phosphates and TE buffer were purchased from Merck Co. (Darmstadt, Germany). L-15 medium, fetal bovine serum (FBS), penicillin-streptomycin, trypsin-EDTA and glutamine were obtained from Gibco BRL (Grand Island, NY, USA). The MDA-MB-231 human breast cancer cell line was obtained from the Food Industry Research and Development Institute (Hsinchu, Taiwan).

Cell culture. The MDA-MB-231 human breast cancer cells were placed into $75-\mathrm{cm}^{3}$ tissue culture flasks and grown at $37^{\circ} \mathrm{C}$ in a humidified atmosphere $\left(\mathrm{CO}_{2}\right.$ was not present $)$ in L-15 medium (Sigma Chemical Co.) containing $10 \%$ 


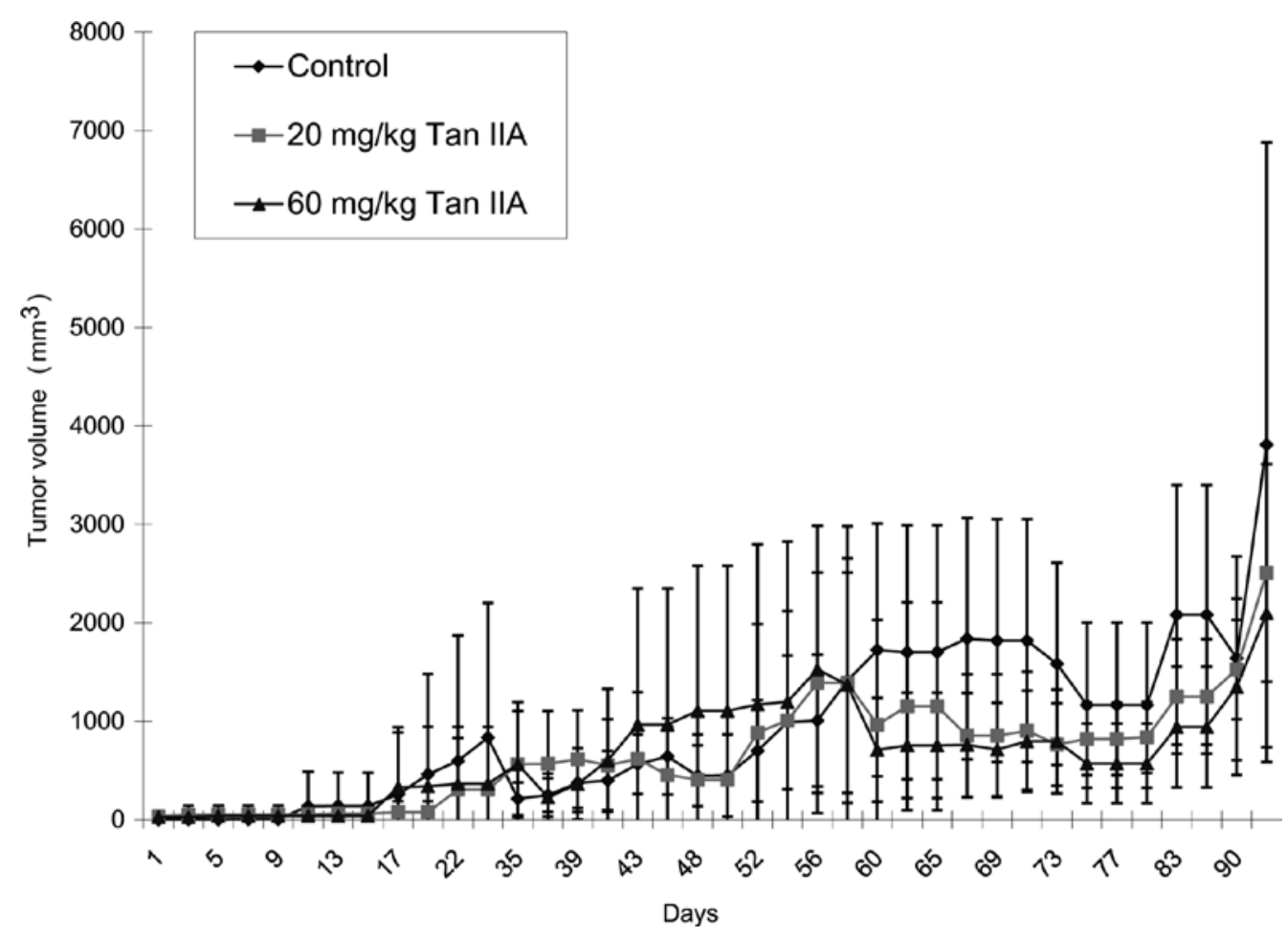

Figure 1. Three-week-old female nude SCID mice were xenografted with MDA-MB-231 cells. On day 28 onwards, the mice were divided randomly into three groups (each group $\mathrm{n}=7)$ to be treated with Tan-IIA $(20 \mathrm{mg} / \mathrm{kg})$ and Tan-IIA $(60 \mathrm{mg} / \mathrm{kg})$. As a control, mice were treated with corn oil $(0.1 \mathrm{ml} / 10 \mathrm{~g}$ body weight). Each agent was administered orally every other day. At the end of the 3-month dosing schedule, the SCID mice were sacrificed by $\mathrm{CO}_{2}$ inhalation on the 97 th day. After xenograft transplantation, mice exhibiting tumors were monitored and the tumor size was measured once every 2 days using calipers. The results showed that Tan-IIA significantly decreased MDA-MB-231 cell xenograft tumor size.

heat-inactivated FBS, $1 \%$ penicillin-streptomycin $(10,000 \mathrm{U} /$ $\mathrm{ml}$ penicillin and $10 \mathrm{mg} / \mathrm{ml}$ streptomycin). The data presented herein are from a minimum of three independent experiments.

The protein expression of LC3-II and Erb-B2 in MDA-MB-231 cells treated with Tan-IIA was determined by western blotting. The cytotoxicity of Tan-IIA on MDA-MB-231 cells has been well documented (11). The result showed that the proliferation of MDA-MB-231 cells was inhibited by Tan-IIA in a dose- and time-dependent manner. $\mathrm{The} \mathrm{IC}_{50}$ was $11.85 \pm 0.29 \mu \mathrm{g} / \mathrm{ml}$ when MDA-MB-231 cells were treated with Tan-IIA for $48 \mathrm{~h}$.

Protein preparation. Approximately $1 \times 10^{6}$ cells $/ 10-\mathrm{cm}$ dish were incubated with Tan-IIA at $0,3,10$ and $25 \mu \mathrm{g} / \mathrm{ml}$ concentrations for $48 \mathrm{~h}$ before the cells were harvested by centrifugation. Protein was extracted as described (16). Briefly, cell pellets were resuspended in modified RIPA buffer $(50 \mathrm{mM}$ Tris- $\mathrm{HCl}$, pH 7.5, $150 \mathrm{mM} \mathrm{NaCl}, 1 \%$ Nonidet P-40, $0.25 \%$ sodium deoxycholate, 1 mM EGTA, $1 \mathrm{mM}$ DTT, $1 \mathrm{mM}$ PMSF, $1 \mathrm{mM}$ sodium orthovanadate, $1 \mathrm{mM}$ sodium fluoride, $5 \mu \mathrm{g} / \mathrm{ml}$ aprotinin, $5 \mu \mathrm{g} /$ $\mathrm{ml}$ leupeptin and $5 \mu \mathrm{g} / \mathrm{ml}$ antipain) for $30 \mathrm{~min}$ at $4^{\circ} \mathrm{C}$. Lysates were immediately centrifuged at $13,000 \mathrm{x}$ g for $20 \mathrm{~min}$ at $4^{\circ} \mathrm{C}$, and the supernatant was collected, aliquoated (50 $\mu \mathrm{g} /$ tube) and stored at $-80^{\circ} \mathrm{C}$ before being assayed. The protein concentrations were measured using the Bradford method (17).

Effects of Tan-IIA on the expression of LC3-II, Erb-B2 and $\beta$-actin in MDA-MB-231 cells. All samples were separated by sodium dodecyl sulfate polyacrylamide (SDS-PAGE) gel electrophoresis (Bio-Rad Life Science Products, Hercules, CA, USA) as previously described (16). The SDS separated proteins were followed by equilibration in transfer buffer (50 mM Tris, pH 9.0, $40 \mathrm{mM}$ glycine, 0.375\% SDS and 20\% methanol) and electro-transferred to Immobilon-P Transfer membranes (Millipore Corporation, Bedford, MA, USA). The blot was then blocked with a solution containing 5\% nonfat dry milk in Tris-buffered saline $[10 \mathrm{mM}$ Tris and $150 \mathrm{mM} \mathrm{NaCl}$ (Sigma Chemical Co.)], containing 0.05\% Tween-20 for $1 \mathrm{~h}$. It was then washed and incubated with antibodies to Erb-B2 (R\&D), LC3-II (Sigma Chemical Co.) and $\beta$-actin (Upstate, Lake Placid, NY, USA) at $4^{\circ} \mathrm{C}$ overnight. After incubating with anti-mouse peroxidase-conjugated antibody (Santa Cruz, Santa Cruz, CA, USA), the signal was visualized by enhanced chemiluminescence (ECL; Amersham Pharmacia Biotech). The detection of $\beta$-actin was used as an internal control in all the data for western blotting.

In vivo MDA-MB-231 cell tumor xenograft model. Threeweek-old female nude SCID mice (NOD.CB 17-Prkdcscid/ Tcu) were xenografted with MDA-MB-231 human breast cancer cells $\left(3 \times 10^{6} / 0.2 \mathrm{ml}\right)$ and maintained in a pathogen-free environment (Laboratory Animal Center of Tzu Chi University, Hualien, Taiwan). On day 28 onwards, the mice were divided randomly into three groups (each group $n=7$ ) to be treated with Tan-IIA ( 20 and $60 \mathrm{mg} / \mathrm{kg}$ of body weight, dissolved in corn oil). As a control, xenografted tumors were separately treated with corn oil $(0.1 \mathrm{ml} / 10 \mathrm{~g}$ body weight). Each agent was administered orally every other day. At the end of the 3-month dosing schedule, the SCID mice were 
A

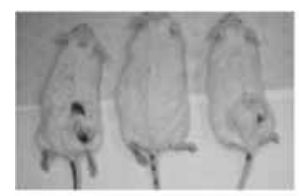

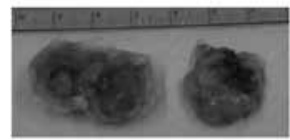

corn oil
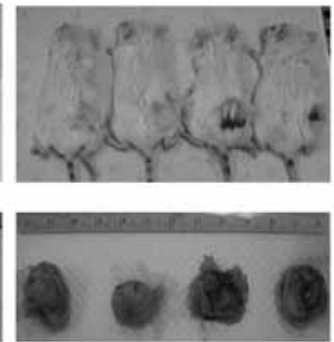

Tan-IIA $20 \mathrm{mg} / \mathrm{kg}$
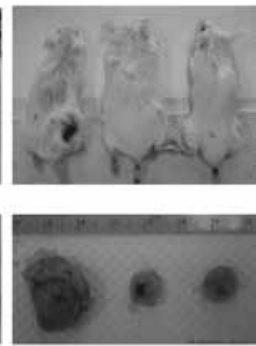

Tan-IIA $60 \mathrm{mg} / \mathrm{kg}$

B $p=0.31$

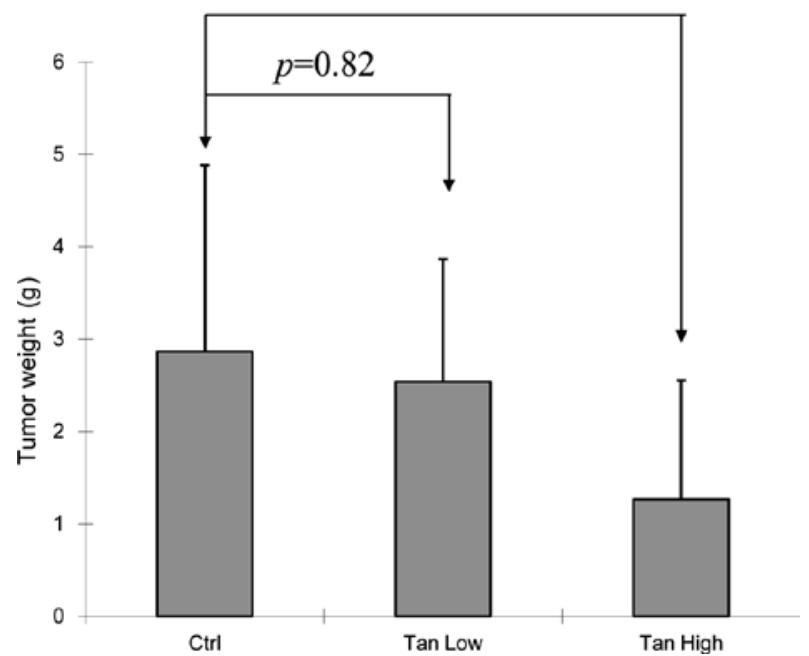

Figure 2. Mice bearing MDA-MB-231 cell xenograft tumors were treated with low dose $(20 \mathrm{mg} / \mathrm{kg})$ and high dose $(60 \mathrm{mg} / \mathrm{kg})$ Tan-IIA for 90 days. As a control, mice were treated with corn oil. (A) At the end of the 3-month dosing schedule, the SCID mice were sacrificed by $\mathrm{CO}_{2}$ inhalation on the 97 th day, and the xenograft tumors were dissected and weighed. (B) The results also showed that high dose $(60 \mathrm{mg} / \mathrm{kg})$ of Tan-IIA significantly decreased the weight of MDA-MB-231 cell xenograft tumors when compared to the control group.

sacrificed by $\mathrm{CO}_{2}$ inhalation on the 97th day. After xenograft transplantation, mice exhibiting tumors were monitored, and the tumor size was measured once every 2 days using calipers. The tumor volume in each animal was estimated according to the formula: Tumor volume $\left(\mathrm{mm}^{3}\right)=\mathrm{Lx} \mathrm{W}^{2} / 2$ (where $\mathrm{L}$ is the length and $\mathrm{W}$ is the width), with the final measurement taken 3 months after tumor cell inoculation. At the same time, the body weight of each animal was measured once every 2 days. The xenograft tumors were dissected and weighed individually, then the proteins were extracted for western blotting. The protein expression of NF- $\kappa \mathrm{Bp} 65$, caspase- 3 and $\beta$-actin was measured by western blotting. Immunoreactive bands were scanned and analyzed using a digital scanning densitometer (Molecular Dynamics, Sunnyvale, CA, USA).

Statistical analysis. Values are presented as the means \pm SD. The Student's t-test was used to analyze the statistical significance and $\mathrm{p}<0.05$ was considered significant for all tests.

\section{Results and Discussion}

The results showed that Tan-IIA significantly decreased the MDA-MB-231 cell xenograft tumor size (Fig. 1). An illustra-

A

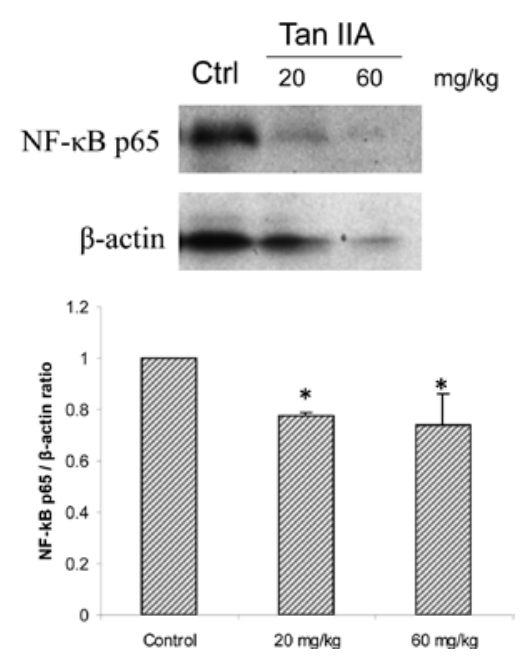

B
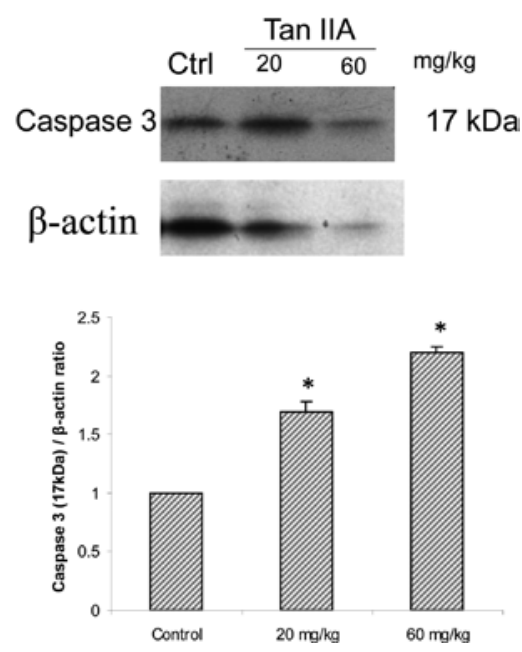

Figure 3. MDA-MB-231 cell xenograft model treated with Tan-IIA decreased NF- $\mathrm{KBp} 65$ expression (A), but increased caspase 3 expression (B) when compared to the control group. Values are expressed as the means $\pm \mathrm{SD}$. "Significant difference at $\mathrm{p}<0.05$ vs. the control group.

tion of a representative animal treated with Tan-IIA relative to the control is shown in Fig. 2A. The results also showed that Tan-IIA $(60 \mathrm{mg} / \mathrm{kg})$ significantly decreased the weight of MDA-MB-231 cell xenograft tumors when compared to the control group (Fig. 2B). All MDA-MB-231 cell xenograft tumors appeared only at the inoculation sites (data not shown). Based on these results, Tan-IIA treatment (both 20 and $60 \mathrm{mg} / \mathrm{kg}$ body weight/per day) by oral administration inhibited MDA-MB-231 cell xenograft tumor growth. In the present study, mice with MDA-MB-231 xenograft tumors received Tan-IIA treatment; these tumors continue to grow slowly, indicating that multiple treatments are necessary to achieve a complete response. However, the results showed that a high dose of Tan-IIA had therapeutic potential in MDA-MB-231 cells in vivo. This is in agreement with other studies $(12,13)$. Our results showed that MDA-MB-231 cell xenograft tumors treated with Tan-IIA decreased NF- $\mathrm{Bp} 65$ (Fig. 3A), but increased caspase 3 expression (Fig. 3B) when compared to the control group. Our results also showed that MDA-MB-231 cells treated with Tan-IIA for $48 \mathrm{~h}$ decreased 
A

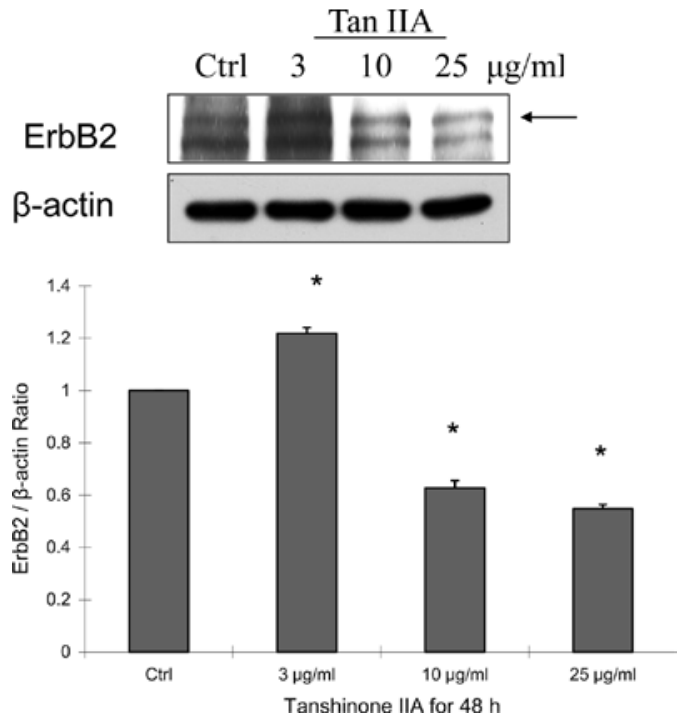

B

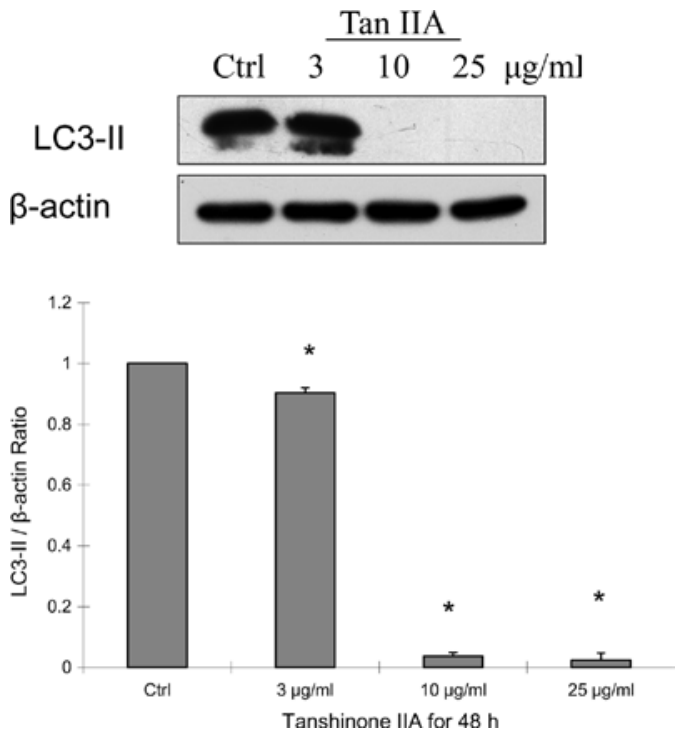

C

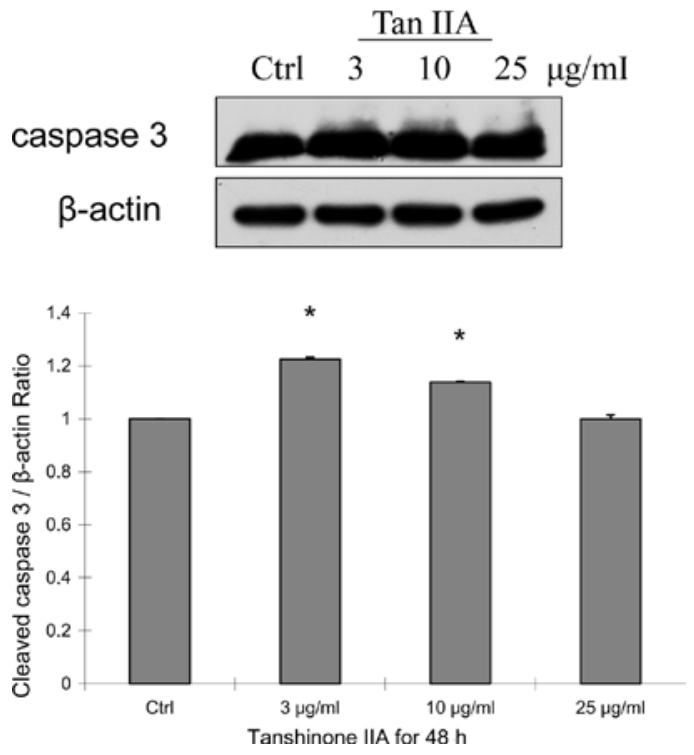

Figure 4. Protein expression of Erb-B2, LC3-II, caspase 3 and $\beta$-actin in MDA-MB-231 cells treated with Tan-IIA for $48 \mathrm{~h}$. The results showed that MDA-MB-231 cells treated with Tan-IIA for $48 \mathrm{~h}$ down-regulated the protein expression of Erb-B2 (A) and LC3-II (B), but increased caspase 3 expression C) in vitro. Values are expressed as the means \pm SD. *Significant difference at $\mathrm{p}<0.05$ vs. the control group. the protein expression of Erb-B2 (Fig. 4A) and LC3-II (Fig. 4B), but increased caspase 3 (Fig. 4C) expression. This is not in agreement with other studies, which showed that xenograft tumors treated with Tan-IIA decreased P53 and bcl-2 expression, but not of cerbB-2 $(12,13)$. The present study provides the first report of Tan-IIA anti-human breast cancer activity through a decrease in Erb-B2 and LC3-II expression in vitro and a decrease in NF-кBp65 expression in an MDA-MB-231 cell xenograft tumor model.

\section{Acknowledgements}

This study was supported by the grant NSC 98-2314-B-303004 from the National Science Council, Department of Health, Executive Yuan, Taiwan, R.O.C.

\section{References}

1. Jemal A, Bray F, Center MM, Ferlay J, Ward E and Forman D: Global Cancer Statistics. CA Cancer J Clin 61: 69-90, 2011.

2. Leung TW and Johnson PJ: Systemic therapy for hepatocellular carcinoma. Semin Oncol 28: 514-520, 2001.

3. Li ZT, Yang BJ and Ma GE: Chemical studies of Salvia miltiorrhiza f. alba. Yaoxue Xuebao 26: 209-213, 1991 (In Chinese).

4. Lin TJ: Antioxidation mechanism of schizandrin and tanshinonatic acid A and their effects on the protection of cardio-toxic action of adriamycin. Shengli Kexue Jinzhan 22: 342-345, 1991 (In Chinese).

5. Liang Y, Yang YM and Yuan SL: Studies on Pharmic mechanism and clinic application of Tanshinone. Tradit Herbal Drugs 31: 304-306, 2000.

6. Su CC and Lin YH: Tanshinone IIA down-regulates the protein expression of ErbB-2 and up-regulates TNF- $\alpha$ in colon cancer cells in vitro and in vivo. Int J Mol Med 22: 847-851, 2008.

7. Su CC, Chen GW, Kang JC and Chan MH: Growth inhibition and apoptosis induction by tanshinone IIA in human colon adenocarcinoma cells. Planta Med 74: 1357-1362, 2008.

8. Cheng CY and Su CC: Tanshinone IIA inhibits Hep-J5 cells by increasing calreticulin, caspase 12 and GADD153 protein expression. Int J Mol Med 26: 379-385, 2010.

9. Cheng CY and Su CC: Tanshinone IIA may inhibit the growth of small cell lung cancer H146 cells by up-regulating the Bax/ Bcl-2 ratio and decreasing mitochondrial membrane potential. Mol Med Rep 3: 645-650, 2010.

10. Chiu TL and Su CC: Tanshinone IIA induces apoptosis in human lung cancer A549 cells through the induction of reactive oxygen species and decreasing the mitochondrial membrane potential. Int J Mol Med 25: 231-236, 2010.

11. Su CC and Lin YH: Tanshinone IIA inhibits human breast cancer cells through increased Bax to Bcl-xL ratios. Int J Mol Med 22: 357-361, 2008.

12. Zhang X, Zhang PR, Chen J and Lü QA: Study on the effect of Tanshinone II A against human breast cancer in vivo. Sichuan Da Xue Xue Bao Yi Xue Ban 41: 62-67, 2010 (In Chinese).

13. Lu Q, Zhang P, Zhang $X$ and Chen J: Experimental study of the anti-cancer mechanism of tanshinone IIA against human breast cancer. Int J Mol Med 24: 773-780, 2009.

14. Zhang PR and Lü QA: study on anticancer activity of tanshinone IIA against human breast cancer. Sichuan Da Xue Xue Bao Yi Xue Ban 40: 245-249, 2009 (In Chinese).

15. Wang X, Wei Y, Yuan S, Liu G, Lu Y, Zhang J and Wang W: Potential anticancer activity of tanshinone IIA against human breast cancer. Int J Cancer 116: 799-807, 2005.

16. Chen HC, Hsieh WT, Chang WC and Chung JG: Aloe-emodin induced in vitro $\mathrm{G} 2 / \mathrm{M}$ arrest of cell cycle in human promyelocytic leukemia HL-60 cells. Food Chem Toxicol 42: 1251-1257, 2004.

17. Bradford MM: A rapid and sensitive method for the quantitation of microgram quantities of protein using the principle of proteindye binding. Anal Biochem 72: 248-254, 1976. 